\title{
A arquitetura da Biblioteca Central da Universidade Federal de Santa Maria e o impacto na preservação do acervo
}

\author{
Lizandra Veleda Arabidian
}

Bibliotecária da Universidade Federal de Santa Maria. Especialista em Gestão em Arquivos pela Universidade Federal de Santa Maria. Mestre em Patrimônio Cultural na Universidade Federal de Santa Maria.

Sônia Elisabete Constante

Professora do Departamento de Documentação da Universidade Federal de Santa Maria. Doutoranda do Programa de Pós Graduação em Comunicação pela Universidade Federal de Santa Maria.

Alberto Brilhante Wolle

Arquiteto da Universidade Federal de Santa Maria. Mestrando em Patrimônio Cultural na Universidade Federal de Santa Maria.

http://dx.doi.org/10.1590/1981-5344/1910

O presente artigo aborda sobre ações de preservação do seu acervo no que se refere a construção e ampliação da Biblioteca Central da Universidade Federal de Santa Maria. Para tanto, foi necessário verificar parte da história da Universidade e da Biblioteca, com foco no seu projeto arquitetônico ao estilo modernista. Por isso, apresenta os arquitetos responsáveis pelo seu projeto e discorre sobre as características da sua construção e da reforma que está sendo realizada no subsolo da Biblioteca. Aponta também, as políticas de preservação adotadas até então, a fim de amenizar os problemas observados. Conclui-se que é necessário formalizar uma política de melhorias no prédio a fim de minimizar os impactos causados pelos agentes biológicos e pelos fatores ambientais, prevenir sinistros e capacitar os servidores para salvaguarda do acervo.

Palavras-chave: Arquitetura; Biblioteca Universitária; Políticas de preservação do acervo; Preservação documental; Universidade Federal de Santa Maria. 


\section{The architecture of Central Library of Federal University of Santa Maria and impact on preservation of archives}

This article focuses on actions to preserve its collections as regards the construction and expansion of the Central Library of the Federal University of Santa Maria. Therefore, it was necessary to check the history of the University and the Library, focusing on its architectural design in the modernist style. Therefore presents the architects responsible for its design and discusses the characteristics of its construction and the reform that is being held in the basement of the Library. Also points out, preservation policies adopted so far in order to reduce the problems observed. Concludes that it is necessary to formalize a policy of building improvements in order to minimize the impacts caused by biological agents and environmental factors, prevent accidents and enable servers to safeguard the collection.

Keywords: Architecture; Federal University of Santa Maria; Policies collection preservation; Preservation of documents; University Library.

Recebido em 04 01.2014 Aceito em 26.02.2015

\section{Introdução}

A primeira universidade criada fora das capitais brasileiras foi a Universidade de Santa Maria, localizada na região central do estado do Rio Grande do Sul (RS), através da Lei n. 3.834 C de 14 de dezembro de 1960. Em 1965, foi renomeada como Universidade Federal de Santa Maria (UFSM).

Atualmente, dispõe de prédios nos municípios de Frederico Westphalen, Palmeira das Missões, Silveira Martins, Cachoeira do Sul e na cidade de Santa Maria, com sedes nos Bairros Centro e Camobi. Nesse último localiza-se a Cidade Universitária Prof. José Mariano da Rocha Filho que possui área territorial total de $1.837,36$ hectares nos quais as edificações perfazem $273.150,92 \mathrm{~m}^{2}$ de área construída ${ }^{1}$.

$\mathrm{Na}$ atualidade a UFSM está na $17^{a}$ posição do ranking das melhores e mais bem conceituadas instituições de ensino superior público e gratuito

\footnotetext{
1 Portal UFSM. Disponível em: <http://sucuri.cpd.ufsm.br/ outros/historico index.php>. Acesso em: 8 out 2014.
} 
do Brasil ${ }^{2}$, em conformidade com o Índice Geral de Cursos (IGC), avaliado pelo do Ministério da Educação (MEC).

O Guia do Estudante UFSM de 2014, elaborado na gestão atual reitor professor Paulo Afonso Burmann e vice-reitor professor Paulo Bayard Dias Gonçalves -, cuja publicação oficial está de acordo com a Resolução n. 08/99 - PROGRAD/DERCA/UFSM, do Conselho de Ensino, Pesquisa e Extensão/UFSM, visa normatizar o Sistema Acadêmico, constituída por mais de 28.000 estudantes, 1.800 docentes e 2.822 servidores técnico-administrativos, distribuídos em quatro campi - Santa Maria, Silveira Martins, Palmeira das Missões e Frederico Westphalen -, além de pólos de educação à distância no país. É ofertado anualmente pela UFSM mais de 250 cursos de ensino médio, técnico, tecnológico, superior, de extensão e de pós-graduação ${ }^{3}$, distribuídos em: 142 Cursos de Graduação (presenciais e a distância) e 138 Cursos de Pós-graduação, entre Mestrado, Doutorado e Especialização. Além dos três Colégios (que oferecem 30 Cursos de Ensino Médio e Pós-Médio) e da Unidade de Educação Infantil Ipê Amarelo, há a Residência Médico-Veterinária e a Residência Médica, com programas em diversas especialidades (GUIA DO ESTUDANTE, 2014).

Considerado como um exemplo único de um conjunto de obras modernistas em grande escala na Região Sul do Brasil, o campus da UFSM é um forte representante de um período impar da arquitetura brasileira. Projetado pelos arquitetos mineiros radicados no Rio de Janeiro, Oscar Valdetaro e Roberto Nadalutti, e tendo o início de construção na década de 1960, em pleno Movimento Moderno, o campus da Universidade Federal de Santa Maria também seguiu os preceitos urbanísticos referentes à sua época, tão em voga e divulgados em efervescentes ideias de arquitetos como Le Corbusier, Lúcio Costa, Irmãos Roberto, entre outros. Para sua consecução foram desenvolvidos cinco planos diretores ao longo do ano de 1961 para uma área de intervenção de 675 hectares, sendo que o último foi aprovado e implantado a partir de 1962 (SCHLEE, 2001 apud ZAMPIERI; MACHADO, 2011).

Outro aspecto modernista presente nos prédios da Cidade Universitária são as obras de arte que acompanham a arquitetura, como as esculturas que estão espalhadas pelo campus, além da integração entre a arquitetura, murais, pinturas e esculturas, como é o caso do mural "Quinhentos anos de invasão da América" localizado no prédio do Centro de Artes e Letras (CAL), de autoria do docente e artista plástico chileno Juan Amoretti.

No projeto, inspirado na Universidade do Brasil (RJ), de Lúcio Costa e Le Corbusier:

[...] Valdetaro e Nadalutti criaram um campus organizado em torno de um eixo estruturador que se desenvolve, em linha reta, do pórtico de acesso principal até a grande praça cívica (delimitada por

\footnotetext{
2 Portal UFSM. Disponível em: <http://sucuri.cpd.ufsm.br/ outros/historico index.php>. Acesso em: 8 out 2014.

${ }^{3}$ Portal UFSM. Disponível em: <http://sucuri.cpd.ufsm.br/_outros/historico_index.php>. Acesso em: 8 out 2014.
} 
prédios isolados e funcionalmente expressivos, como o teatro, o museu e o planetário). Tal eixo tem seu ponto focal no prédio da Reitoria (único edifício em altura). As demais unidades distribuem-se paralelamente ao eixo e agrupam-se segundo setores acadêmicos (prédios lineares, com dois pavimentos sobre pilotis) (SCHLEE, 2003).

Acompanhando essa perspectiva arquitetônica, foi inaugurado em 3 de setembro de 1972, o prédio de número 30, destinado a abrigar a sua Biblioteca Central, localizado entre o Hospital Universitário de Santa Maria (HUSM) e a União Universitária. A proposta era seguir uma forte hierarquização de vias, sublimando a subdivisão da área em pequenas parcelas, mas possuindo como pano de fundo uma grande área verde aberta para a implantação de suas edificações, quase que totalmente isoladas.

\section{Biblioteca Central da UFSM}

A Biblioteca Central Manoel Marques de Souza, "Conde de Porto Alegre", foi fundada juntamente com a criação da Universidade em 1960, ao reunir as coleções bibliográficas das Faculdades de Farmácia, Medicina, Odontologia, Veterinária, Agronomia, Belas Artes, Politécnica, Filosofia, Ciências e Letras. Mas, inicialmente, estava sediada no então prédio da Administração Central, no centro da cidade, hoje a antiga reitoria. Atualmente está vinculada à Pró-Reitoria de Administração, sendo um órgão suplementar da Reitoria, coordenando, tecnicamente, as quatorze bibliotecas setoriais da UFSM ${ }^{4}$.

A finalidade da Biblioteca é colocar à disposição da comunidade universitária a informação bibliográfica atualizada, de forma organizada, favorecendo o desenvolvimento do ensino, da pesquisa e da extensão.

O sistema utilizado é o SIE - Sistema Integrado para o Ensino, desenvolvido pelo Centro de Processamento de Dados da UFSM que abrange todos os módulos para atender as demandas da Biblioteca.

Atualmente dispõe de 101.548 livros; 7.288 folhetos; 19.821 obras entre teses, dissertações e monografias; 212.032 fascículos de periódicos e 5.675 itens dentre os demais tipos de materiais ${ }^{5}$.

Seu horário de atendimento externo é das $7 \mathrm{~h} 30 \mathrm{~m}$ às $22 \mathrm{~h}$, de segunda à sexta-feira e aos sábados das $8 \mathrm{~h}$ às $12 \mathrm{~h}$. Diariamente circulam em suas dependências uma média de 3.500 usuários. No primeiro

\footnotetext{
${ }^{4}$ Biblioteca Setorial dos Centros de Tecnologia, de Ciências Sociais e Humanas, Educação Física e Desportos, de Educação, de Ciências Rurais, de Artes e Letras e de Ciências Naturais e Exatas; do Colégio Técnico e Industrial; do Colégio Politécnico; de Cachoeira do Sul; da Unidade Descentralizada de Educação Superior de Silveira Martins; do Colégio Agrícola de Frederico Westphalen; do Centro de Educação Superior Norte de Palmeira das Missões e Frederico Westphalen.

${ }^{5}$ Período: setembro de 2014.
} 
semestre de 2014 foram feitos em torno de 180 mil empréstimos na Biblioteca Central.

\subsection{Os Arquitetos envolvidos na obra}

O prédio que hoje abriga a Biblioteca fora projetado pelos mesmos arquitetos responsáveis pelo projeto da Cidade Universitária. Segundo Zampieri (2011), Oscar Valdetaro e Roberto Nadalutti formaram-se na Escola Nacional de Belas Artes, após a reforma do ensino realizada por Lucio Costa. Ambos tiveram um papel fundamental na normatização do edifício hospitalar no país:

Os dois arquitetos em conjunto projetaram vários hospitais pelo país inteiro, entre eles a Maternidade Escola Assis Chateubriand, da Universidade do Ceará (1956); o Hospital das Clínicas de Ribeirão Preto (1956); e o Hospital Santa Mônica, em Belo Horizonte (1962). (ZAMPIERI, 2011, p. 110).

Também teriam assumido em 1958 o projeto do Hospital das Clínicas da Universidade Federal do Rio Grande do Sul, inicialmente desenvolvido por Jorge Moreira.

Filho de João Valdetaro de Amorim e Mello e Maria Jullia Torres, Oscar Valdetaro de Torres e Mello nasceu em 2 de outubro de 1924 e faleceu em 5 de agosto de 1976, aos 51 anos. Integrou o grupo responsável pelo projeto do Estádio do Maracanã, no Rio de Janeiro.

Roberto Nadalutti nasceu em 1922 e faleceu aos 80 anos em maio de 2002. Foi professor na Escola Nacional de Saúde Pública (ENSP) na qual lecionava arquitetura hospitalar. Além disso, projetou o Pavilhão Henrique Aragão da Fundação Oswaldo Cruz (1954-1960) e o Pavilhão Santa Maria no campus hospitalar da Beneficência Portuguesa (1950), ambos no Rio de Janeiro (ARRUSUL, 2009).

\subsection{A Biblioteca Central da UFSM e a arquitetura moderna}

Construída entre 1969 e 1972 (Figura 1) seria a "menina dos olhos" dos arquitetos dentre as demais edificações do campus.

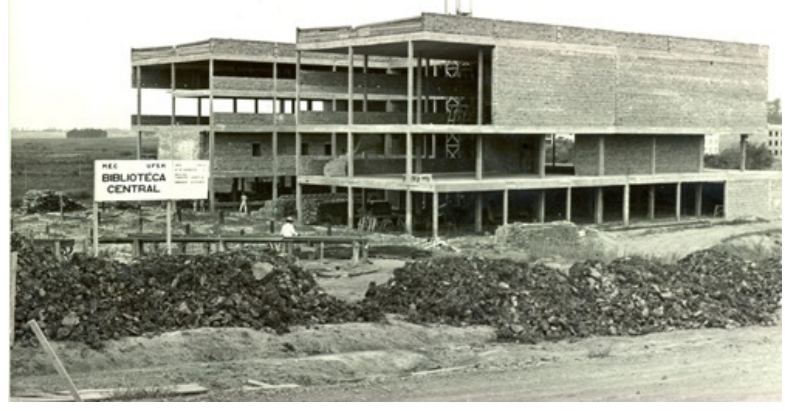


Figura 1 - Construção da Biblioteca Central

Fonte: Departamento de Arquivo Geral.

Sua estrutura de concreto armado distribui-se numa área de $8.237 \mathrm{~m}^{2}$ (Figura 2) nos quais "A edificação é um volume puro de base retangular com pátio central, resolvida em três pavimentos, sendo um subsolo, o térreo, e o pavimento superior além do mezanino." (ZAMPIERI, 2011, p. 154)

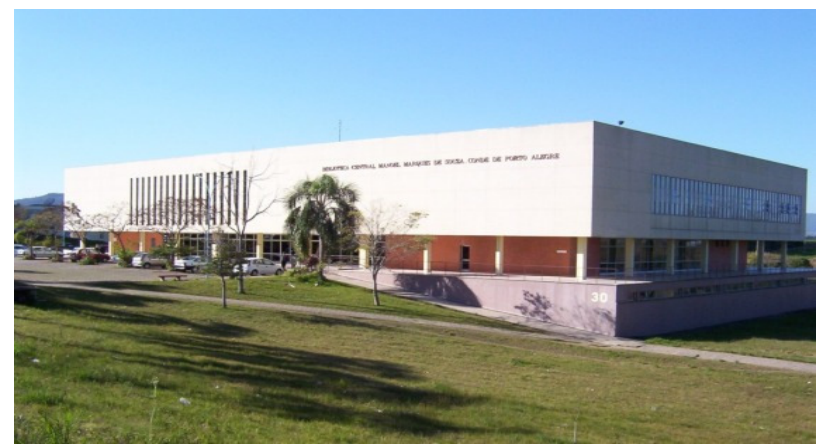

Figura 2 - Fachada da Biblioteca Central com o estacionamento à frente Fonte: Arquivo da Biblioteca Central.

Schlee $(2003)^{6}$ completa a descrição salientando que:

O pavimento térreo é recuado em relação ao restante da edificação, de maneira a criar uma varanda contínua ao redor da construção, toda ela marcada pelo ritmo modulado dos pilares (pilotis) e pelo fechamento envidraçado. Já o segundo pavimento é compacto e suas fachadas foram tratadas conforme exigia a orientação solar. Enquanto a varanda sugere transparência e convida para a leitura, o segundo pavimento sugere fechamento e indica $o$ recolhimento apropriado para o estudo. Na biblioteca da UFSM, a Villa Savoye (Le Corbusier, 1929/31) encontra-se com o ambulatório do Instituto de Puericultura e Pediatria da UFRJ (Jorge Moreira, 1949/53), resultando numa composição correta e apropriada.

No projeto original da Cidade Universitária, a Biblioteca Central ficaria ao lado do lago artificial que, por problemas técnicos de topografia, nunca chegou a ser executado e inundado. Ainda assim, o entorno possui o curso d'água natural, atualmente canalizado, que alimentaria esse lago. Desse modo, devido a sua proximidade com o curso d'água existente, o terreno no qual fora construída era como um 'banhado' que necessitou ser previamente terraplenado e, posteriormente, aterrado para viabilizar o estacionamento à sua frente.

Seu plano de necessidades pode ser assim descrito:

\footnotetext{
${ }^{6}$ Disponível em: <http://www.docomomo.org.br/seminario\%205\%20pdfs/020R.pdf>. Acesso em: 10 maio 2012.
} 
a)Subsolo:

- Acervo Geral,

- Mesas de estudo distribuídas entre o acervo,

- Espaço para leitura de jornais e revistas semanais, com expositores, poltronas e mesa para leitura,

- Setor de Mapas com 8 mapotecas,

- Sala de Descarte,

- Sanitários (masculino e feminino),

- Setor de Referência,

- Setor de Periódicos,

- Setor de Reparo,

- Cozinha,

- Reprografia terceirizada;

b) Térreo

- Almoxarifado,

- Direção,

- Cozinha,

- Guarda-volumes,

- Portaria,

- Sala Multimídia,

- Salão de Estudos,

- Secretaria,

- Setor de Aquisição,

- Setor de Empréstimo,

- Setor de Processos Técnicos,

- Serviço de Comutação Bibliográfica,

- Sanitários (masculino e feminino);

c)Primeiro andar:

- Sala de Consulta aos Diários Oficiais,

- Acervo de Teses, Dissertações e Monografias,

- Salão de Estudos,

- Sanitários (masculino e feminino);

d)Mezanino: 


\section{- Cabines de estudo individuais.}

O prédio possui um sistema de ar-condicionado central para uma área de $4.900 \mathrm{~m}^{2}$, porém nunca entrou em operação, apesar dos fatores climáticos serem determinantes para a danificação de um acervo, já que a Região Sul apresenta características distintas no seu clima, com quatro estações bem definidas e com frequentes oscilações de temperatura e umidade. Esses fatores ambientais, em que o Rio Grande do Sul está enquadrado na zona fundamental temperada ou " $\mathrm{C}$ " e no tipo fundamental "Cf" ou temperado úmido", aliado a falta de adequação estrutural do prédio, auxiliam no aceleramento do crescimento de fungos/mofos e bactérias, necessitando assim, de procedimentos adequados para a conservação do acervo. ${ }^{8}$

Da mesma forma, foi projetado espaço para dois elevadores sociais, entretanto estes nunca foram instalados. Por outro lado, existem 6 (seis) elevadores monta-cargas, com 3 (três) em cada lado do acervo, ligando o subsolo ao primeiro andar, que estão funcionando satisfatoriamente, para o transporte de materiais.

Apesar de ser construído para abrigar a Biblioteca Central, desde 1993, divide espaço com o Curso de Arquitetura e Urbanismo que ocupa com salas de aula, laboratórios, ateliês e a coordenação do Curso. Até 2011, dividia o espaço também com uma agência da Caixa Econômica Federal, hoje realocada em prédio próprio.

Em setembro de 2011, o movimento estudantil ocupou a Reitoria da Universidade por doze dias, e como resposta a uma das suas reivindicações foi a eles prometido pelo Magnífico Reitor Felipe Martins Müller a realização de um estudo para a criação de uma sala de acesso digital e mesas de estudos, sete dias por semana e 24 horas por dia, no espaço que a Caixa Econômica Federal desocupou quando da sua mudança. Porém, até o presente momento, o espaço continua ocioso, embora esteja prevista a sua destinação para ampliação do hall e guardavolumes da Biblioteca, e para uma central de atendimento ao aluno.

Reforçando suas características do período modernista, onde a arquitetura se presta de suporte às artes, encontra-se no hall de entrada da biblioteca o painel "A História do papel, da escrita e do livro", de autoria do artista plástico Eduardo Trevisan. Desse modo, "Devido ao seu estilo arquitetônico, a obra não é apenas de arquitetura, mas, também, de arte." (MEDEIROS, 2010)

Quanto ao terreno no qual fora construída, como se mencionou anteriormente, trata-se de um solo instável por ser próximo de um curso d'água natural e que por essas características requeria estudo que não fora previsto à época de sua construção. Devido a essa inadequação, as lajes e paredes do subsolo apresentam problemas estruturais (como rachaduras e inclinações consideráveis) agravados pela sobrecarga do acervo que armazena:

\footnotetext{
${ }^{7}$ Portal Revistas USP. Disponível em: <http://coralx.ufsm.br/ifcrs/clima.htm>. Acesso em: 14 out. 2014.

${ }^{8}$ Portal Topgyn. Disponível em: <http://www.topgyn.com.br/conso01/rio grande sul/index.php>. Acesso em: 15 maio 2012.
} 
Os cerca de 83.000 exemplares do acervo pesam e fazem com que o piso ceda pouco a pouco. Os R $\$ 526.000$ do REUNI para a aquisição de livros entre 2009 e 2010, fazem o número de estantes ser insuficiente para comportar tamanha injeção de títulos. Tudo isso em meio à luz e circulação de ar pouco apropriados - o que prejudica os usuários e gera colônias de fungos e bactérias que se proliferam no recinto. (BRESSAN; MILENICZUK, 2010).

Apesar das evidentes inclinações no solo e das rachaduras horizontais nas paredes que essas causaram as demais estruturas (pilares e vigas) não apresentam problemas para suportarem as cargas para as quais foram previstas inicialmente.

Embora o crescimento natural do acervo tenha agravado a situação, entende-se que apenas evidencia uma inadequação de uso recorrente nos projetos arquitetônicos voltados às Bibliotecas. Apesar dos programas de necessidades originais terem sido atendidos no projeto arquitetônico elaborado por Valdettaro e Nadalutti, as alterações de uso dos espaços internos no decorrer dos anos e a não implantação de equipamentos trouxeram uma série de inconvenientes para os usuários da Biblioteca:

A democratização do acesso ao acervo permitiu que os usuários adentrassem num espaço originalmente projetado para guarda de livros com janelas suficientes apenas para ventilação natural nos períodos de manutenção dos equipamentos, os quais nunca foram instalados completamente. Somando-se a isso, por questões de segurança e do pó, oriundo do arruamento contíguo à edificação, essas janelas foram lacradas potencializando o desconforto dos usuários. (ARABIDIAN, 2013).

A Biblioteca passa atualmente por um processo de ampliação do seu espaço físico ${ }^{9}$ onde, em virtude dos recursos aportados para a obra, do extenso programa de necessidades e das urgências imediatas para acomodação do acervo adquirido através do Programa de Reestruturação e Expansão das Universidades Federais (REUNI), optou-se, por meio de um grupo de trabalho composto por bibliotecários e arquitetos da UFSM, pela ampliação da área destinada ao acervo de livros, ou seja, o segmento de maior importância da edificação.

Essa ampliação deu-se no início de 2011 e estava prevista sua conclusão ao término de 2013, no entanto, devido a alguns problemas estruturais, ainda não foi possível ocupar a área nova. Por isso, nova licitação está sendo elaborada para atender as necessidades, como o Plano de Prevenção e Proteção Contra Incêndio - PPCI ${ }^{10}$, além dos seguintes projetos: climatização; de proteção nas aberturas e paisagismo

\footnotetext{
${ }_{9}^{9}$ A autoria do projeto é do Arquiteto da Pró-Reitoria de Infraestrutura Alberto Brilhante Wolle.

${ }^{10}$ Portal UFSM/PPCI. Disponível em: <http://coral.ufsm.br/midia/?p=21029>. Acesso: 13 out 2014.
} 
na parte externa da obra; reforma da área da Biblioteca central contemplando os três pavimentos.

Na Figura 3 é apresentado a Biblioteca Central com a apresentação da planta fachada, incluindo a área nova (anexo).

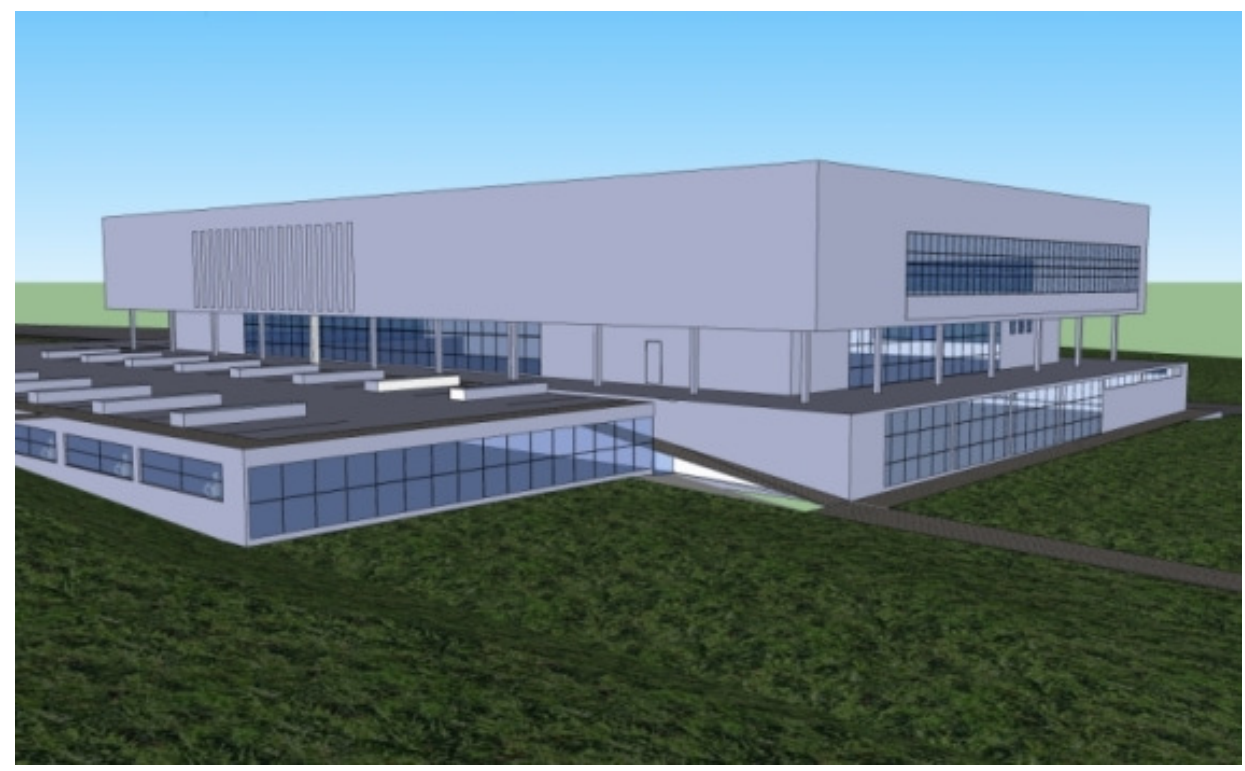

Figura 3 - Prospecto da Biblioteca após a ampliação

Fonte: Arquiteto Alberto Brilhante Wolle.

Assim, "[...] aumentará em 50\% o espaço da biblioteca, o equivalente a uma expansão em $800 \mathrm{~m}^{2}$ do prédio, garantindo o bom armazenamento de livros por mais 15 ou 20 anos, conforme previsão de Brilhante." (BRESSAN, MILENICZUK, 2010).

Tal projeto deve-se ao cuidado do arquiteto em não descaracterizar a leitura do prédio, que é representativo da época, o que aconteceria caso fosse construído um anexo atrás ou ao lado da Biblioteca, além de atender questões de funcionalidade por parte dos usuários. Num segundo momento, está prevista a revitalização e relocação dos espaços internos e a recuperação da sua fachada.

\subsection{Programa de preservação na Biblioteca Central da UFSM}

Os documentos e materiais bibliográficos buscam contribuir para a história e cultura social, por isso a criação de um programa de preservação, iniciado através da identificação de ações possíveis de serem implementadas, por meio de estudos que contemplem o levantamento do estado de conservação dos prédios, entorno e coleções, são etapas importantes a serem consideradas em um processo de planejamento. Para Cassares (2011), é fundamental o levantamento do estado de conservação das coleções, uma vez que é essencial avaliar as necessidades de cada obra para somente após um estudo da real situação do acervo definir procedimentos como higienização adequada das estantes 
e de um adequado sistema de segurança, mas também pelas suas condições de transporte e uso.

Esses cuidados são explicitados na forma de políticas de preservação, através de programas, na qual são previstas ações para a conservação preventiva e administração de emergências, como danos provocados por água, fogo, vandalismo e agentes biológicos. De posse dos resultados o avaliador poderá determinar as atividades que serão previstas no planejamento mediante valor estimado, priorizando deste modo as ações imediatas a serem executadas em um programa de preservação. Contudo, sensibilizar para a importância do estabelecimento de uma política de preservação não é tarefa fácil, pois requer o reconhecimento dessa necessidade dentre todas as pessoas envolvidas com os processos que precedem e seguem a disponibilização do material: servidores e demais usuários.

No contexto acadêmico, a biblioteca universitária da UFSM desempenha papel fundamental no fomento a pesquisa, ensino e extensão dos 310 cursos distribuídos nas diversas modalidades (graduação, pósgraduação, ensino médio e técnico) ${ }^{11}$.

Em razão da importância do seu acervo, desde 2009 está sendo feito estudos que visam estabelecer ações de prevenção, conciliando a preservação do material bibliográfico com a difusão do conhecimento registrado a fim de garantir o acesso à informação científica de qualidade. Desse modo, requer inúmeros cuidados relativos à armazenagem e manuseio dos materiais, aos fatores ambientais (temperatura e umidade relativa do ar; radiação da luz e qualidade do ar), bem como minimizar a ação dos agentes biológicos (fungos, roedores, insetos) que atuam na deterioração dos acervos e requerem a adequação e manutenção dos prédios que os custodiam.

No caso da Biblioteca Central, já foram realizados alguns estudos nos acervos como:

a) o projeto de pesquisa em andamento, desde 2009, intitulado "Biodeterioração da Biblioteca Central e do Arquivo Geral da UFSM", coordenado pela Profa. Dra. Denise de Souza Saad;

b) a Dissertação de Mestrado em Engenharia Civil pela Universidade Federal de Santa Maria de Luciana Manzoni Pereira, intitulada "Avaliação das Patologias e da Biodeterioração da Biblioteca Central da UFSM" (2010);

c) a monografia "Agentes biológicos no acervo da Biblioteca Central da Universidade Federal de Santa Maria/RS" de autoria da Bibliotecária Lizandra Veleda Arabidian, orientado pela Professora Mestre Sônia Elisabete Constante (2011);

\footnotetext{
${ }^{11}$ Portal UFSM/Indicadores. Disponível em: <http://portal.ufsm.br/indicadores/select/34>. Acesso em: 10 jul. 2012.
} 
d) a pesquisa "Aspectos Ergonômicos/Ambientais na Biblioteca Central da Universidade Federal de Santa Maria: Iluminação e Ventilação" de Vanessa Michelon Cocco entre outros autores (2011);

e) a pesquisa de ensino "Da teoria às práticas: diagnóstico de conservação de acervos da Biblioteca Central da UFSM", com a colaboração de Lizandra Veleda Arabidian e orientação da Professora Mestre Sônia Elisabete Constante (2012);

f) a pesquisa intitulada "Avaliação da biodeterioração e das condições ambientais no acervo da Coleção Teses e Coletânea da Biblioteca Central da Universidade Federal de Santa Maria" tema da dissertação de mestrado da Bibliotecária Lizandra Veleda Arabidian orientada pela Professora Doutora Denise de Souza Saad, no pós-graduação Patrimônio Cultural da UFSM (2013);

g) a pesquisa de ensino "Diretrizes de Preservação: uma proposta para a Biblioteca Central da UFSM", com a colaboração de Lizandra Veleda Arabidian e orientação da Professora Mestre Sônia Elisabete Constante (2013).

Sabe-se também, que existe uma estreita relação entre a durabilidade das obras e as condições ambientais do local onde são armazenados os materiais. Não obstante, os fatores ambientais de degradação do papel manifestam-se mais agressivos no clima subtropical úmido tornando-se fundamental estabelecer medidas para o seu controle racional e sistemático. Em suma, a conjunção desses fatores e agentes pode contribuir para a redução da usabilidade dos materiais de arquivos e bibliotecas e para a saúde daqueles que os utilizam e gerenciam.

Com relação à arquitetura da Biblioteca, contemplando a sua construção e ampliação, foi verificado que as instalações, tanto do prédio atual, como da nova área, necessitam de reformas. Na área construída, houve dilatação do concreto, apresentando infiltrações, rachaduras e condensação de água nas clarabóias (vidros) em razão da oscilação de temperatura e umidade, aliados a falta de ventilação. A ideia das clarabóias foi de possibilitar a incidência de luz natural, porém, como não existe abertura ocorre a condensação, favorecendo o surgimento de agentes biológicos $e$, consequentemente, danifica 0 acervo ali posicionado. Para apontar soluções para o problema das clarabóias estão sendo utilizadas as recomendações de órgãos competentes como 0 Conselho Nacional de Arquivos (CONARQ) e a Biblioteca Nacional. Somando-se a isso, existe a preocupação com o isolamento térmico da laje com a proposta de criação de um ambiente de convivência com 
espaços para leitura e cultura, através de projeto de paisagismo já submetido à aprovação.

No restante do prédio da Biblioteca, de acordo com as adequações identificadas nas pesquisas, devem ser priorizadas ações de conservação nos acervos. Como ação imediata, e já iniciada, relacionada à temperatura ambiental, foi instalado no subsolo o sistema split para atender as necessidades dos usuários e, posteriormente, deverão ser contemplados os demais andares. Mas, é preciso ter um controle de temperatura e umidade, com a aquisição de equipamentos como o termo-higrômetro e desumidificadores, que deverão ser projetados para uma nova licitação, no entanto sem prazo definido. Está em andamento a elaboração do projeto que prevê a reforma geral pretendida pela Direção da Biblioteca Central que compreende a retirada do forro de eucatex, além de solucionar problemas estruturais, desde rebocos até o rebaixamento de paredes.

Outra previsão é a iluminação, cujo projeto de ampliação desenvolvido pelos técnicos da UFSM já contempla a imediata adequação do acervo já existente, com a instalação de um novo sistema lumínico, que além de atender os lumens exigidos por norma, contribuirá para a economia de energia, visto que sensores de presença serão instalados nos corredores individualmente. $\mathrm{Na}$ iluminação natural deverão ser substituídas as janelas emperradas.

Nos casos de sinistros (como alagamentos ou incêndios), especialmente os incêndios, deve-se seguir o PPCI proposto pela UFSM, com as novas adequações, como já está sendo aplicado na nova área.

Existe também um cuidado especial com os procedimentos de higienização do acervo, e desta forma, um servidor técnico realiza treinamento periódico para funcionários de limpeza terceirizados que respondem pela limpeza das estantes e prateleiras diariamente, de acordo com um cronograma previsto pela Direção da Biblioteca.

De posse desse estudo, visando a criação de um programa de preservação e das discussões que se espera obter dentre os bibliotecários e demais servidores, acredita-se que será possível estabelecer outras medidas como a aquisição de equipamentos necessário para a conservação do acervo e a sensibilização quanto a necessidade de inserir esses cuidados na rotina da Biblioteca.

\section{Considerações finais}

Passados cinquenta anos de existência da Universidade Federal de Santa Maria, o prédio da Biblioteca Central continua a ser referência arquitetônica do campus. Tal valorização pode ser referenciada pelo projeto "Cidade de Papel" idealizado e executado por alunos e professores dos Cursos de Arquitetura e Urbanismo, Desenho Industrial Programação Visual e História da UFSM com parceria do Núcleo de Estudos em Patrimônio e Memória (NEP) da UFSM e o Conselho Municipal de Patrimônio Histórico e Cultural de Santa Maria (COMPHIC). 
No projeto, foram produzidas maquetes em papel de prédios representativos do patrimônio histórico da cidade e, posteriormente, encartadas em um jornal de grande circulação, entre dezembro de 2010 e maio de 2011. A primeira maquete publicada foi uma réplica do prédio da Biblioteca Central visualizada na Figura 5, tendo por objetivo aproximar a população de Santa Maria do seu patrimônio, e também para marcar os 50 anos da instituição. ${ }^{12}$

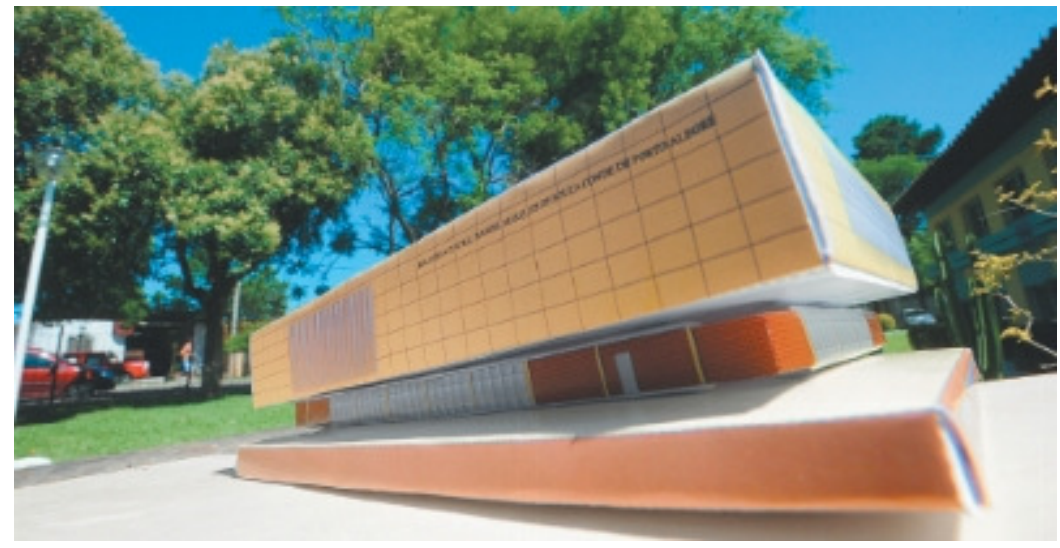

Figura 5 - A maquete da Biblioteca Central da UFSM

Fonte: Lauro Alves/Diário de Santa Maria. Disponível em:

<http://sucuri.ufsm.br/noticias/noticia.php?id=31853>. Acesso em: 2 mar. 2015.

Atualmente, o prédio está sendo ampliado a fim de reorganizar os ambientes internos e viabilizar o crescimento do acervo por um período superior a 30 anos. Contudo, com o lento andamento das obras e a tradicional ocupação de importantes áreas da Biblioteca com usos distintos da sua função original, a exemplo da recém-removida Caixa Econômica Federal e do Curso de Arquitetura e Urbanismo, que está sendo construído em outra área do campus, com previsão de término para o ano de 2016, representam aproximadamente uma quarta parte de sua área física. Deste modo, torna-se inviável a adequação e a correção de velhos problemas, que afetam seus usuários, servidores e o acervo como:

a) os problemas de acessibilidade decorrentes das escadas internas que impedem cadeirantes ou demais pessoas com dificuldade de mobilidade à chegarem ao acervo ou as cabines de estudo no mezanino;

b) a ausência de piso tátil para orientação dos deficientes visuais;

c) a existência de caixas-bueiros em diversos pontos do subsolo que já foram responsáveis pelo alagamento deste;

d) os diversos focos de possíveis sinistros, como os banheiros e as cozinhas, que podem acarretar em inundações;

\footnotetext{
12 Portal Clicrbs. Disponível em: <http://gruporbs.clicrbs.com.br/blog/2010/12/16/diario-de-santa-maria-lancao-projeto-cidade-de-papel/>. Acesso em: 2 mar. 2015.
} 
e) a existência de um jardim interno que não é utilizado como espaço de convivência e apenas agrava a umidade do acervo além de trazer consigo agentes biológicos nocivos a conservação deste;

f) a iluminação artificial inadequada, mas necessária devido à falta de iluminação natural;

g) a falta de ventilação que pode acarretar em um grande desequilíbrio térmico e, consequente concentração de mofo e umidade, principalmente na área destinada ao acervo, fator este que favorece o surgimento de microrganismos.

Espera-se que estes sejam sanados com as obras de ampliação e reformas previstas. Entretanto, questões como a acessibilidade para portadores de deficiência ou mobilidade reduzida só poderão ser contempladas de maneira satisfatória com a devolução para o uso da Biblioteca de importantes áreas atualmente ocupadas com outras funções.

Quanto à iluminação, foi realizada uma vistoria pelos engenheiros do CREA/POA em novembro de 2013, com o auxílio da aparelhagem Luxímetro Panlux da Gossen. Na ocasião, foi adotada como procedimento a observação in loco para a verificação da quantidade de luz que estava sendo incidida diretamente no acervo do subsolo em conformidade com as recomendações da equipe. Nos estudos realizados até o presente momento, constatou-se que a iluminação no subsolo da Biblioteca Central é bem diversificada, pois em alguns locais, embora haja luminárias em quantidade suficiente, muitas destas contem lâmpadas ou reatores queimados, propiciando a proliferação de microrganismos. Por isso, uma solução apontada seria a reforma colocando lâmpadas adequadas conforme recomendação do CONARQ e da Biblioteca Nacional, que poderá resolver parte do problema de iluminação sem causar danos aos materiais.

Embora a arquitetura da Biblioteca Central apresente pontos negativos, no que diz respeito ao impacto na conservação do acervo, acredita-se que estes podem ser amenizados com a formalização de políticas de preservação desenvolvidos através de programas, com as melhorias iniciadas, como é o caso da construção da nova área e as campanhas de preservação ${ }^{13}$. Para tanto, é importante dar continuidade aos estudos, através de projetos que focalizem temas como condições climáticas e outras características locais para propostas de melhorias no prédio da Biblioteca e, consequentemente, no acervo.

Desse modo, com os estudos realizados foi verificada a necessidade de adotar medidas preventivas que valorizem a arquitetura do prédio da Biblioteca Central, mas sem intervenções na fachada do mesmo como critério preponderante na definição de ações futuras no programa de

13 Portal UFSM/Biblioteca/Conservação do acervo. Disponível em: <http://w3.ufsm.br/biblioteca/index.php/servicos/conservacao-do-acervo>. Acesso em: 14 out. 2014. 
preservação, já que o prédio é um patrimônio arquitetônico, aliada também, as demais práticas de conservação do acervo que custodia refletindo assim, na salvaguarda dessas duas facetas do patrimônio histórico e cultural da comunidade acadêmica da Universidade Federal de Santa Maria.

\section{Referências}

ARABIDIAN, L. V. Avaliação da biodeterioração e das condições ambientais os acervos da coleção teses e coletânea da biblioteca central da Universidade Federal de Santa Maria/RS. 2013. Dissertação (Mestrado em Patrimônio Cultural) - Programa de Pós-Graduação Profissional em Patrimônio Cultural, Universidade Federal de Santa Maria, Santa Maria, 2013.

ARRUSSUL, L. G. Arquitetura, urbanismo, educação: o campus da Universidade Federal de Santa Maria. 2009. Dissertação (Mestrado em Arquitetura) - Programa de Pesquisa e Pós-Graduação da Capes, Universidade Federal de Santa Catarina, Santa Catarina, 2009.

BRESSAN, O. S.; MILENICZUK, L. Novos capítulos na história da Biblioteca Central. InfoCampus, Santa Maria, 15 de set. 2010. Disponível em: <http://w3.ufsm.br/infocampus/?p=2344>. Acesso em: 10 maio 2012.

CASSARES, N. C. Política de preservação de documentos arquivísticos. Disponível

em: <http://www.arquivoestado.sp.gov.br/saesp/ciclopalestras9.pdf> Acesso em: 13 agosto de 2012.

SCHLEE, A. R. Reproduzindo modelos: o plano piloto do campus da Universidade Federal de Santa Maria, RS. In: SEMINÁRIO DOCOMOMO BRASIL, 5., 2003, São Carlos. Anais... Santa Maria, 2003. Disponível em: <http://www.docomomo.org.br/seminario\%205\%20pdfs/020R.pdf>.

Acesso em: 10 maio 2012.

UNIVESIDADE FEDERAL DE SANTA MARIA. Guia do estudante UFSM 2014. Disponível em: <http://sucuri.cpd.ufsm.br/_pdf/docs/guiadoestudante2014.pdf> Acesso em: 7 out. 2014.

WOLLE, A. B. [História e ampliação da Biblioteca Central]. Entrevistadoras: Camille Chiarelli e Patricia Michelotti. .txt, Santa Maria, v. 4, n. 13, 24 de maio de 2011. Disponível em: <http://w3.ufsm.br/revistatxt/>. Acesso em: 10 maio 2012.

ZAMPIERI, R. V. Campus da Universidade Federal de Santa Maria: um testemunho, um fragmento. 2011. Dissertação (Mestrado em Arquitetura) - Universidade Federal do Rio Grande do Sul. Faculdade de Arquitetura. Programa de Pesquisa e Pós-Graduação em Arquitetura, Porto Alegre, 2011. 
ZAMPIERI, R. V.; MACHADO, A. S. A UFSM e uma possível preservação através da interdisciplinaridade. In: SEMINÁRIO DOCOMOMO BRASIL, 9., 2011, Brasília - DF. Anais... Brasília, 2011. Disponível em: <http://www.docomomo.org.br/seminario\%209\%20pdfs/066_PB_ORAUFSM-ART_renata_zampiere.pdf>. Acesso em: 12 maio 2012. 